\title{
Фразеологизмы советской эпохи и нового времени (на материале словарей)
}

\author{
Чигринова Е.А. \\ Волгоградский государственный медицинский университет, \\ Россия, 400131, г. Волгоград, площадь Павших Борцов, 1 \\ E-mail: kat-belka1990@yandex.ru
}

\begin{abstract}
Аннотация. Важную роль в обучении современному русскому языку имеет изучение лексического состава каждой эпохи. Несмотря на многочисленность публикаций по данному направлению, в научных работах лексике и фразеологии советского периода и нового времени уделено недостаточное внимание. Целью данного исследования является сбор и анализ фразеологизмов русского языка советского периода, составление их классификации с точки зрения происхождения. Представлены итоги анализа картотеки, собранной на основе словарей, найдены и приведены первоисточники (кинематограф и тексты песен), из которых новые фразеологические единицы вошли в активный словарный запас советского общества. Сопоставительный анализ отобранных устойчивых выражений позволил выявить наиболее распространенные типы фразеологизмов по классификации В.В. Виноградова. Полученные результаты позволяют расширить знания о культурных, политических, моральных, социальных и экономических ценностях советского общества. Материал может быть использован в вузовских курсах лексикологии, стилистики, общего языкознания, спецкурсах по лингвокультурологии, социолингвистике.
\end{abstract}

Ключевые слова: фразеология, советская эпоха, типы фразеологизмов, кинематограф, песни.

Для цитирования: Чигринова Е.А. 2020. Фразеологизмы советской эпохи и нового времени (на материале словарей). Вопросы журналистики, педагогики, языкознания, 39 (4): 662-670. DOI $10.18413 / 2712-7451-2020-39-4-662-670$

\section{The Soviet Union and new union prazeological units (based on dictionaries)}

\author{
Ekaterina A. Chigrinova \\ Volgograd State Medical University, \\ 1, Pavshikh Bortsov Sq., Volgograd, 400131, Russia \\ E-mail: kat-belka1990@yandex.ru
}

\begin{abstract}
The general regularity of development of the science of stable idiomatic phrases is that, being directly related to all types of human activity, it constantly changes through the emergence of new ones, the withering away of outdated ones and changes in the meaning of some phraseological units. While teaching of modern Russian language is important to study the lexical composition of each era. Despite the large number of researches in this area, in papers of the last decades less attention is given to the Soviet Union and new union vocabulary and phraseology. The purpose of this research is to collect and analyze the phraseological units of the Russian language of the Soviet Union, to compile their classification according to their origin. The results of the analysis of the card-index based on dictionaries, their primary sources: Cinema and song texts, of which new phraseological units entered the active vocabulary of Soviet society, are presented. A comparative analysis of the selected stable expressions made it possible to identify the most common types of phraseological units according to the classification of V.V. Vinogradov. The results make a certain contribution in development of the vocabulary and
\end{abstract}


phraseology of the Russian language of the Soviet Union, expand knowledge about the cultural, political, moral, social and economic values of Soviet society. The material can be used in university courses in lexicology, stylistics, general linguistics, special courses in cultural linguistics, sociolinguistics.

Keywords: phraseology, Soviet Union, types of phraseological units, cinema, songs.

For citation: Chigrinova E.A. 2020. The Soviet Union and new union prazeological units (based on dictionaries). Issues in Journalism, Education, Linguistics, 39 (4): 662-670 (in Russian). DOI $10.18413 / 2712-7451-2020-39-4-662-670$

\section{Введение}

Фразеологический состав языка находится в постоянном развитии, поскольку сменяющиеся исторические периоды оставляют свой след не только в развитии техники, культуры, медицины, но и в виде новых языковых единиц, словосочетаний, которые сохраняются в лексике и передаются следующему поколению. Мы разделяем мнение Б.А. Ларина, который считает, что семантически связанные сочетания слов «всегда косвенно отражают воззрения народа, общественный строй, идеологию своей эпохи» [Ларин, 1977, с. 156].

Устойчивые выражения обладают особой экспрессивностью, украшают и делают более выразительной речь человека, употребляющего их в разговоре с собеседником. Фразеологические единицы входят в состав всех языков мира, изучая их семантику, индивиды получают знания о конкретном обществе, народе, ведь именно в них «лингвокультурная общность отражает свое национальное самосознание» [Телия, 1996, с. 9].

Существует множество взглядов на объем понятия «фразеологизм». В.Н. Телия считает, что «все устойчивые сочетания слов, независимо от их характерологических признаков» являются предметом изучения фразеологии [Телия, 1996, с. 58]. Согласно имеющимся исследованиям, автор выделяет шесть классов подобных выражений: идиомы, фразеологические сочетания, паремии (пословицы и поговорки), штампы, клише, а также крылатые выражения. Для правильного использования в определенном контексте того или иного устойчивого выражения необходимо знать его семантику и историю возникновения.

Общепринятым является выделение двух групп фразеологизмов: исконные и заимствованные, каждая из которых положена в основу многочисленных классификаций, основанных на различных критериях: синтаксический [Шахматов, 1941], структурный [Абакумов, 1942], семантический [Виноградов, 1977], стилистический [Ефимов, 1954] аспекты. В исследованиях русских и зарубежных ученых [Шанский, 1941; Гужва, 1978; и др.] особое место занимает изучение происхождения и возникновения устойчивых выражений. Одна из наиболее подробных типологий, основанной на видах источников фразеологизмов, представлена в работе Л.А. Булаховского [1952]. По мнению ученого, фонд русской фразеологии пополнился под влиянием таких элементов, как (1) пословицы и поговорки; (2) профессионализмы; (3) выражения из анекдотов и шуток; (4) цитаты и образы из библии; (5) реминисценции из античности; (6) перевод иностранных устойчивых выражений; (7) крылатые слова писателей.

В данных исследованиях рассматриваются некоторые группы фразеологизмов, зародившихся в русской лексике под влиянием определенных традиций, явлений, научных открытий, литературы, а также пришедших из других языков. Однако ни в одной из перечисленных научных работ не описывается происхождение устойчивых выражений в русском языке советского периода. По справедливому замечанию Г.М. Шипицыной, лексику выделенного периода важно изучать по причине того, что она оказала «значительное влияние на формирование обновленной национальной картины мира последующих периодов жизни россиян» [Шипицына, 2016, с. 22]. В связи с этим целью настоящего исследования является анализ национальной культуры, отражаемой во фразеологизмах советской эпохи 
и нового времени, взявших свое начало из кинематографа и текстов песен, а также их систематизация по четырем лексико-семантическим группам, выделенным В.В. Виноградовым. Поставленная цель требует решения следующих задач: изучить статью В.В. Виноградова «Об основных типах фразеологических единиц в русском языке»; собрать картотеку из советских фразеологизмов на основе словарей; определить происхождение и семантику каждого из них; выявить ведущий тип устойчивых выражений.

Лексический строй - это область языка, которая в наиболее обобщенном виде принимает, отражает и передает от говорящего слушающему все происходящее в определенный этап развития конкретного общества [Джонич, 2016; Коган, 2017]. Советская эпоха характеризуется появлением новых слов под влиянием различных факторов, прежде всего, развития науки и техники, что повлекло за собой возникновение ранее неизвестных номинаций профессий, ячеек общества, предметов быта [Нгуен Лан Фыонг, 2017].

Авторы многочисленных исследований рассматриваемого периода считают, что в языке «устойчиво закреплены многочисленные фразеологические словосочетания, также являющиеся экспрессивными синонимами уже существующих нерасчлененных обозначений предметов, действий и т. д., причем фразеологический состав языка непрестанно пополняется» [Русский язык..., 1968, с. 122].

У истоков советской фразеологии стояли Г.О. Винокур [1923], В.В. Виноградов [1977], Л.И. Ройзензон, Е.А. Малиновский, А.Д. Хаютин [1975] и другие лингвисты. Исследователи отмечали, что зарождение выделенной дисциплины было связано с появлением новых оборотов речи, особенности которых требовали объяснений.

Исследования в области устойчивых выражений советского периода и нового времени сегодня активно представлены в лингвистике. Особенно релевантным в последнее время стал анализ их источников происхождения и значения. Так, А.И. Казакова в авторском исследовании отмечает, что «дискурсивное пространство кинофильмов является естественной средой порождения языковых единиц косвенно производной семантики дискурсивных ФЕ, которые закрепляются в языковом сознании всего этнокультурного сообщества» [Казакова, 2014, с. 11].

Возникновению новых лексических единиц и выражений способствовало много факторов: развитие производства, культурные и экономические связи с дружественными народами, искусство, музыка, кинематограф. Последнее явление в советский период активно развивалось, что, безусловно, повлияло на расширение лексического состава русского языка. Советское кино берет свое начало с 20 -х годов XX века и уже в 30-е «становится частью повседневности. Делясь воспоминаниями, те, чьи детство и юность пришлись на эти годы, говорили о кино как об одном из самых ярких и праздничных первых впечатлений» [Русина, 2019, с. 17]. Исходя из описанного восприятия зрителями «нового кино» можно предположить, что яркие словосочетания и предложения из речи любимых киногероев активно использовались в кругу семьи, близкого окружения, общества, и со временем становились крылатыми выражениями и фразеологизмами.

\section{Объекты и методы исследования}

Объектом исследования является русская фразеология, предметом - фразеологизмы советской эпохи и нового времени. Нами проанализировано около ста пятидесяти фразеологических выражений, появившихся в период с 1960 по 1990 г. В работе использованы описательный метод для экспликации рассматриваемых языковых явлений, метод сплошной выборки, позволивший создать авторскую картотеку фразеологических единиц. Для выявления значения анализируемых единиц были применены семантический и контекстуальный анализы, поскольку некоторое количество фразеологизмов являются полисемантичными и заключенное в них значение, зависит от контекста речи. 
Материалом для исследования послужили «Толковый словарь языка Совдепии» [Мокиенко, Никитина, 1998] и «Большой словарь крылатых слов русского языка» [Берков и др., 2000]. Методом сплошной выборки из названных источников были отобраны более 150 фразеологических единиц, появившихся в советском союзе. Весь фактический материал был классифицирован по двум группам с учетом происхождения устойчивых выражений и далее разбит на подгруппы по тематике и типам фразеологических сочетаний, выделенных В.В. Виноградовым.

\section{Результаты и обсуждение}

Зарождение и развитие фразеологии в советском языкознании связано, прежде всего, с именем В.В. Виноградова. Одной из основополагающих работ лингвиста является статья «Об основных типах фразеологических единиц в русском языке» [Виноградов, 1977]. Степень и характер семантической слитности лексических компонентов устойчивых выражений послужили основанием для предложенной ученым классификации типов фразеологизмов. Основываясь на названном критерии, В.В. Виноградов выделил:

- фразеологические единства («... значение целого никогда не равняется сумме значений элементов» - «взять свое») [Виноградов, 1977, с. 143];

- фразеологические сращения («... тип словосочетаний абсолютно неделимых, неразложимых, значение которых совершенно независимо от их лексического состава, от значений их компонентов...»- «собаку съел») [Виноградов, 1977, с. 145];

- фразеологические сочетания («... характерно наличие синонимического, параллельного оборота, связанного с тем же опорным словом, характерно сознание отделимости и заменимости фразеологически несвободного слова...» - «затронуть чувство чести, затронуть чьи-либо интересы, затронуть гордость и т.п.») [Виноградов, 1977, с. 159].

С развитием фразеологии классификация, предложенная В.В. Виноградовым, была дополнена еще одним видом идиом - «фразеологические выражения». Данный термин появился в науке благодаря Н.M. Шанскому и обозначал «устойчивый в своём составе и употреблении фразеологический оборот, который не только является семантически членимым, но и состоит целиком из слов со свободным значением» [Шанский, 1996, с. 69]. В рамках данной статьи мы принимаем во внимание перечисленные разновидности фразеологизмов и условно считаем их составляющими одной типологии.

Проанализировав имеющиеся подходы в области изучения устойчивых выражений и различные определения термина «фразеологизм» в лингвистике, мы уточнили данное понятие применительно к целям и задачам нашего исследования. Поскольку в центре нашего внимания - появившиеся в определенный временной промежуток идиомы, источниками которых явились кинофильмы и тексты песен, мы уточняем термин «фразеологизм» и понимаем его как устойчивые, неделимые, готовые к воспроизведению в речи, выражения или словосочетания о доминирующих культурных ценностях, ставших стереотипными в определенном обществе.

Проведенное нами исследование показало, что большое количество фразеологических единиц пополнили советский состав фразеологии благодаря кинематографу. Яркие названия, экспрессивные высказывания персонажей кинокартин нашли отражение в лексиконе советского зрителя. Фактический материал позволяет утверждать, что устойчивые высказывания преимущественно взяты из заглавий фильмов. Данная подгруппа представлена следующими как однозначными, так и многозначными фразеологизмами:

- выражение «место встречи изменить нельзя» - фраза, которая стала употребляться после выхода одноименного многосерийного художественного фильма (1979 г.) Станислава Говорухина. Она несет в себе следующую семантику: «невозможность предотвращения исхода событий и изменения места предполагаемой развязки» [Берков и др., 2000, с. 268]; 
- крылатая фраза «ирония cyдьбы»), источником происхождения которой стало название фильма Эльдара Рязанова, обозначает «слепую случайность, необычное, странное стечение жизненных обстоятельств» [Берков и др., 2000, с. 203];

- фразеологическое единство, аналогичное имени главного персонажа - «кот Леоnольд», произошедшее из всем известного детского мультфильма «Приключения кота Леопольда». Данным словосочетанием можно охарактеризовать добродушного, миролюбивого человека, уклоняющегося от ссор и драк [Берков и др., 2000];

- фразеологическое выражение «нет мира под оливами» - название художественного фильма 1950 года, употребляемое для описания «тревожной и непростой ситуации» [Берков и др., 2000, с. 321];

- «плата за страх» - русское заглавие франко-итальянского художественного фильма 1953 года, несущее в себе семантику «о действиях, поступках, иногда аморальных, противоправных, совершаемых под какой-либо угрозой благополучию, положению в обществе, жизни» [Берков и др., 2000, с. 173];

- фразеологизм «зигзаг удачи» повествует «о превратностях судьбы, непостоянстве удачи», его источником стало название советского фильма 1968 года Э. Рязанова [Берков и др., 2000, с. 184];

- идиома «вооружен и очень опасен» - заголовок одноименного советского художественного фильма 1978 года; обычно используется в речи для того, чтобы передать собеседнику «образную характеристику человека, организации, государства, представляющих угрозу для окружения» [Берков и др., 2000, с. 90];

- устойчивое выражение «доживем до понедельника», появившееся после картины С.И. Ростоцкого, имеет значение времени: «подождем, потом видно будет, что делать; поживем-увидим» [Берков и др., 2000, с. 146].

Высказывания героев кинофильмов также цитировались и активно употреблялись в речи. Среди отобранных можно выделить следующие:

- реплика Шурика, главного героя художественного фильма «Операция Ы и другие приключения Шурика» 1965 года - «Надо, Федя, надо!», вошедшая в активный словарный запас как советского, так и современного человека, несет в себе семантику: «шутливо убеждают собеседника в необходимости что-либо сделать» [Берков и др., 2000, с. 294];

- фразеологическое выражение «информащия к размышлению» - фраза из телесериала «Семнадцать мгновений весны» (1973 г.) - многозначно: «1) это стоит запомнить, взять на заметку; над этим стоит подумать; 2) полезные сведения, заставляющие думать, размышлять» [Берков и др., 2000, с. 202].

Наше исследование показало, что источником развития советской лексики явились еще и высказывания персонажей мультфильмов, к примеру, известные приключения зайца и волка из мультфильма «Ну погоди!». Именно после его выхода на экраны, выражение «Hy, заяи, ну погоди!» стало крылатым и по настоящее время обозначает «шутливую угрозу» [Берков и др., 2000, с. 333].

Таким образом, проанализировав фактический материал, нами было выявлено, что в период существования Советского Союза около 30 \% всех новых фразеологических выражений появились благодаря кинематографу. Кинорежиссеры и сценаристы создавали свои картины, отражая в них менталитет советского народа, основные проблемы и переживания, отношения между людьми. В свою очередь зрители выделяли для себя наиболее важные, по их мнению, и полно передающие значимые моменты из жизни персонажей, устойчивые сочетания слов, которые в языке стали выступать «в роли знаковмикротекстов» [Казакова, 2014, с. 15]. Устойчивые высказывания, источником которых стали мультфильмы, составили $10 \%$ в нашей картотеке. Стоит отметить тенденцию к употреблению в речи фразеологизмов данной подгруппы не только у детей, но, в большей степени, у взрослых. 
Особого внимания заслуживают выражения, первоисточником которых стали тексты песен. Выделенная группа включает в себя наибольшее количество фразеологизмов и составляет $60 \%$ от общего объема фактического материала. Среди идиом, имевших широкое распространение в лексике нового времени, прежде всего, можно выделить подгруппу устойчивых выражений, содержащих в своей семантике уверенность в силе человеческого разума и человеческих возможностей: «и на Марсе будут яблони цвести»название песни В. Мурадели на стихи Е. Долматовского; «еще не вечер»- рефрен песни В. Высоцкого 1968 года, сочетающий в себе два значения: «еще не все потеряно, многое можно изменить, исправить, наверстать; это не предел; можно (предстоит) достичь еще большего» [Берков и др., 2000, с. 161];

- идиома - «вся жизнь впереди, надейся и жди» - строка из песни А. Экимяна на стихи Р. Рождественского «Не надо печалиться» 1975 года, обозначающая уверенность в будущем [Берков и др., 2000].

Следующая выделенная нами подгруппа устойчивых выражений, взятых из песен, - фразеологизмы о внешности, о безграничных возможностях человека: «элегантный, как рояль» - строка из шутливой студенческой песенки «Громко лаяли собаки» повествует «о человеке, одетом с претензией на элегантность» [Берков и др., 2000, с. 558]; «ведь он артист, он повторит» - строка из припева «Песни на бис» Р. Паулса, передающее значение «готовности повиноваться требованиям публики, начальства, готовности исполнить свой долг» [Берков и др., 2000, с. 67].

В ходе нашего исследования были найдены как моносемичные фразеологизмы, например, строчка из песни Олега Митяева «как здорово, что все мы здесь сегодня собрались», выражающая «радость от общения с друзьями, единомышленниками» [Берков и др., 2000, с. 212], так и полисемичные, к примеру, «вода, вода, кругом вода»- строчка из припева песни «Как провожают пароходы» Аркадия Ильича Островского. Указанный оборот имеет два значения: «1. О большом водном пространстве (река, море); о значительном скоплении грунтовых вод; 2. Шутл. Пустые разговоры, болтовня» [Берков и др., 2000, c. 82].

Нами также выделены устойчивые выражения, содержащие в своей семеме несколько смыслов, отличающиеся от вышерассмотренного. Их особенность состоит в том, что одно из значений устарело, а другое фразеологизировалось и отразилось в тексте, например: «мы за иеной не постоим» - рефрен всех трех строф песни Булата Окуджавы «Нам нужна одна победа» из фильма А. Смирнова «Белорусский вокзал» (1991 г.). В словаре Беркова находим два значения данного выражения: «1. О готовности идти на любые жертвы ради достижения высокой цели (знач., идущее от песни). 2. Не беспокойтесь, расплатимся (знач. старое, первичное по отношению к песенному)» [Берков и др., 2000, c. 283]. В контексте песни актуализируется первый смысл рассматриваемого выражения. Полисемичных фразеологизмов в годы советской власти образовалось не так много. В числе проанализированных нами подобных найдено всего лишь 40, что практически в два раза меньше количества моносемичных фразеологических оборотов.

\section{Заключение}

Результаты проведенного исследования показывают, что в советский период русская фразеология пополнилась большим количеством устойчивых выражений, среди которых из текстов песен были взяты 97 единиц, из фильмов -49 , из мультфильмов - 8 . В своей семантике фразеологизмы отражали характеристику человека, его чувства и отношение к различным жизненным ситуациям; описание окружающей действительности и природы, обстоятельства происходящих событий, необходимость выполнения определенных действий. 
Установленный список фразеологических единиц также был распределен по группам, основанием для выделения которых стали работы В.В. Виноградова и Н.М. Шанского. Таким образом, при составлении классификации выяснилось, что больше всего в советскую эпоху было образовано фразеологических единств («люди доброй воли»; «железная леди»; «из-под прилавка» и др.). На втором месте по численности оказались фразеологические выражения («надо Федя, надо!»; «женщина, которая поет»; «загадочная нату$p a »)$. Фразеологических сращений из общего количества единиц было выделено всего четыре («живая газета»; «театр абсурда»; «красная чума» и «красная гвоздика»), а фразеологические сочетания в рамках нашей картотеки представлены не были.

Итак, исследование фразеологического состава русского языка советской эпохи и нового времени позволяет сделать вывод о том, что их происхождение в большой степени связано с развитием кинематографа и песенного искусства. Полученные в процессе анализа результаты позволяют доказать предположение некоторых ученых, к примеру, Л.Л. Федоровой, считающей, что разные виды дискурса, в частности публицистический, опираются на «штампы и клише советской эпохи» [Федорова 2016, с. 19]. Устойчивые выражения, ставшие популярными в обществе, постепенно расширяясь, перерастают в культурные стереотипы. Сделанные выводы вносят вклад в развитие теории и практики изучения современного русского языка советского периода.

Подобные исследования позволяют определить основные ценности, картину мира, отдельно рассматриваемого общества, народа в конкретный промежуток времени, так как именно лексика отражает в своем составе все открытия и культуру людей, объединенных по месту жительства, профессии, интересам и т.д. В дальнейшем можно рассмотреть возникшие в другие десятилетия фразеологические единицы, а также провести сравнительный анализ для установления их общих и специфических черт.

\section{Список источников}

1. Берков В.П., Мокиенко В.М., Шулежкова С.Г. 2000. Большой словарь крылатых слов русского языка: ок. 4000 единиц. М., Рус. словари, Астрель, Аст, 623 с.

2. Винокур Г.О. 1923. О революционной фразеологии. Леф, 2: 104-118.

3. Мокиенко В.М., Никитина Т.Г. 1998. Толковый словарь языка Совдепии. СПб., ФолиоПресc, 704 c.

\section{Список литературы}

1. Абакумов С.И. 1942. Современный русский литературный язык. М., Советская наука, $184 \mathrm{c}$.

2. Булаховский Л.А. 1952. Русский литературный язык первой половины XIX века. Лексика и общие замечания о слоге. Т 1. Киев, Радянська школа, 447 с.

3. Виноградов В.В. 1977. Об основных типах фразеологических единиц в русском языке. В кн. Избранные труды. Лексикология и лексикография. Под ред. В.Г. Костомарова. М., Наука: $140-161$.

4. Гужва Ф.К. 1978-1979. Современный русский литературный язык. В 2 ч. Под ред. Н.А. Кондрашова. Киев, Вища школа, 246 с.

5. Джонич В. 2016. Историко-этимологический и лингвокультурный анализ русских фразеологизмов. Научный результат. Вопросы теоретической и прикладной лингвистики, 3 (9): $28-34$.

6. Ефимов А.И. 1954. О языке художественных произведений. М., Учпедгиз, 288 с.

7. Казакова А.И. 2014. Особенности формировании фразеологической семантики в дискурсивном пространстве отечественного киноискусства. Автореф. дис... канд. филол. наук. Волгоград, $28 \mathrm{c.}$

8. Коган Е.С. 2017. Советский и постсоветский периоды в зеркале севернорусской диалектной лексики и фразеологии. Политическая лингвистика, 4: 108-113. 
9. Ларин Б.А. 1977. История русского языка и общее языкознание. Избр. работы. М., Просвещение, 224 с.

10. Нгуен Лан Фыонг. 2017. Тематика ментально значимых крылатых выражений и фразеологизмов русского языка. Мир науки, культуры, образования, 6 (67): 544-548.

11. Ройзензон Л.И. 1975. Очерки истории становления фразеологии как лингвистической дисциплины. Самарканд, Самарк. ун-т, 129 с.

12. Русина Ю.А. 2019. История советского кино. Екатеринбург, Изд-во Урал. ун-та, 104 с.

13. Русский язык и советское общество. 1968. Социолого-лингвистическое исследование. В 4 кн. Под ред. М. В. Панова. Москва, Наука, 4 т.

14. Телия В.Н. 1996. Русская фразеология. Семантический, прагматический и лингвокультурологический аспекты. М., Языки русской культуры, 288 с.

15. Федорова Л.Л. 2016. Образы русской речи» в современных массмедиа. Медиалингвистика, 3 (13): 19-30.

16. Шанский Н.М. 1996. Фразеология современного русского языка. СПб., Специальная литература, 192 с.

17. Шахматов А.А. 1941. Синтаксис русского языка. Под ред. Е.С. Историной. М., Учпедгиз, $620 \mathrm{c.}$

18. Шипицына Г.М., Мамонова Ю.О. 2016. Общий взгляд на лексикон русского языка советского периода. Научные ведомости Белгородского государственного университета. Серия: Гуманитарные науки, 14 (235): 21-28.

\section{References}

1. Abakumov S.I. 1942. Sovremennyy russkiy literaturnyy yazyk [Modern Russian literary language]. M., Publ. Sovetskaya nauka, 184 p.

2. Bulakhovskiy L.A. 1952. Russkiy literaturnyy yazyk pervoy poloviny XIX veka. Leksika i obshchie zamechaniya o sloge [Russian literary language of the first half of the 19th century. Lexicon and general notes about the syllable]. Vol. 1. Kiev, Publ. Radyans'ka shkola, $447 \mathrm{p}$.

3. Vinogradov V.V. 1977. Ob osnovnykh tipakh frazeologicheskikh edinits v russkom yazyke [On the main types of phraseological units in the Russian language]. In: Izbrannye trudy. Leksikologiya $\mathrm{i}$ leksikografiya [Selected Works. Lexicology and Lexicography]. Ed. V.G. Kostomarova. M., Publ. Nauka: $140-161$.

4. Guzhva F.K. 1978-1979. Sovremennyy russkiy literaturnyy yazyk [Modern Russian literary language]. In. 2 ch. Ed. N.A. Kondrashova. Kiev, Publ. Vishcha shkola, 246 p.

5. Dzhonich V. 2016. Istoriko-etimologicheskij i lingvokul'turnyj analiz russkih frazeologizmov. [Historical-etymological and linguocultural analysis of Russian phraseological units]. Scientific result Nauchnyj rezul'tat. Voprosy teoreticheskoj i prikladnoj lingvistiki, 3 (9): 28-34.

6. Efimov A.I. 1954. O yazyke khudozhestvennykh proizvedeniy [About the language of works of art]. M., Publ. Uchpedgiz, 288 p.

7. Kazakova A.I. 2014. Osobennosti formirovanii frazeologicheskoy semantiki v diskursivnom prostranstve otechestvennogo kinoiskusstva [Features of the formation of phraseological semantics in the discursive space of Russian cinema]. Abstract dis ... cand. philol. sciences. Volgograd, $28 \mathrm{p}$.

8. Kogan E.S. 2017. Sovetskij i postsovetskij periody v zerkale severnorusskoj dialektnoj leksiki i frazeologii. [The Soviet and post-Soviet periods in the mirror of the Northern Russian dialect vocabulary and phraseology]. Politicheskaya lingvistika, 4: 108-113.

9. Larin B.A. 1977. Istoriya russkogo yazyka i obshchee yazykoznanie. Izbr. raboty [History of the Russian language and general linguistics. Fav. work]. M., Publ. Prosveshchenie, 224 p.

10. Nguen Lan Fyong. 2017. Tematika mental'no znachimyh krylatyh vyrazhenij i frazeologizmov russkogo yazyka. [Topics of mentally significant winged expressions and phraseological units of the Russian language]. Mir nauki, kul'tury, obrazovaniya, 6 (67): 544-548.

11. Rojzenzon L.I. 1975. Ocherki istorii stanovleniya frazeologii kak lingvisticheskoj discipliny [Essays on the history of phraseology as a linguistic discipline]. Samarkand, Samark. un-t, $129 \mathrm{p}$.

12. Rusina Yu.A. 2019. Istoriya sovetskogo kino [The history of Soviet cinema]. Ekaterinburg, Publ. Izd-vo Ural. un-ta, 104 p. 
13. Russkiy yazyk i sovetskoe obshchestvo. Sotsiologo-lingvisticheskoe issledovanie [Russian language and Soviet society. Sociological and linguistic research.]. 1968. In. 4 kn. Ed. M.V. Panova. Moskva, Publ. Nauka, 4 vol.

14. Teliya V.N. 1996. Russkaya frazeologiya. Semanticheskiy, pragmaticheskiy i lingvokul'turologicheskiy aspekty [Russian phraseology. Semantic, pragmatic and linguocultural aspects]. M., Publ. Yazyki russkoy kul'tury, 288 p.

15. Fedorova L.L. 2016. Obrazy russkoj rechi v sovremennyh massmedia. [Images of Russian speech in modern mass media]. Medialingvistika, 3 (13): 19-30.

16. Shanskiy N.M. 1996. Frazeologiya sovremennogo russkogo yazyka [Phraseology of the modern Russian language]. SPb., Publ. Spetsial'naya literatura, 192 p.

17. Shakhmatov A.A. 1941. Sintaksis russkogo yazyka [Syntax of the Russian language]. Ed. E.S. Istorinoy. M., Publ. Uchpedgiz, 620 p.

18. SHipicyna G.M., Mamonova YU.O. 2016. Obshchij vzglyad na leksikon russkogo yazyka sovetskogo perioda. [General view of the lexicon of the Russian language of the Soviet period]. Nauchnye vedomosti Belgorodskogo gosudarstvennogo universiteta. Ser.: Gumanitarnye nauki, 14 (235): $21-28$.

\section{ИНФОРМАЦИЯ ОБ АВТОРЕ}

Чигринова Екатерина Александровна, кандидат филологических наук, преподаватель кафедры русского языка и социальнокультурной адаптации Волгоградского государственного медицинского университета, г. Волгоград, Россия

\section{INFORMATION ABOUT THE AUTHOR}

Ekaterina A. Chigrinova, Candidate of philological sciences, Lecturer, Department of Russian Language and Socio-Cultural Adaptation, Volgograd State Medical University, Volgograd, Russia 